Bryn Mawr College

Scholarship, Research, and Creative Work at Bryn Mawr

College

Psychology Faculty Research and Scholarship

Psychology

2018

\title{
Attachment and adaptation to breast cancer: The mediating role of avoidant emotion processes
}

T. Brandão

M S. Schulz

Bryn Mawr College, mschulz@brynmawr.edu

P. M. Matos

Let us know how access to this document benefits you.

Follow this and additional works at: https://repository.brynmawr.edu/psych_pubs

Part of the Psychology Commons

\section{Custom Citation}

Schulz, M. 2018. "Attachment and adaptation to breast cancer: The mediating role of avoidant emotion processes." European Journal of Cancer Care 27.2: e12830.

This paper is posted at Scholarship, Research, and Creative Work at Bryn Mawr College. https://repository.brynmawr.edu/psych_pubs/65

For more information, please contact repository@brynmawr.edu. 
Attachment and Adaptation to Breast Cancer: The Mediating Role of Avoidant Emotion

Processes

\begin{abstract}
Attachment insecurity is associated with difficulties in adapting to cancer. Accumulating evidence points to the influence of avoidant emotion processes in this association. This study explored this pathway by examining the association between attachment insecurity and quality of life in women with breast cancer, and by exploring the mediating role of two avoidant emotion processes in this association. Women with breast cancer $(\mathrm{N}=155)$ completed measures of attachment, emotional suppression, emotional awareness, and quality of life. Avoidance of attachment was positively associated with emotional suppression $(\beta=.29, \mathrm{p}<.01)$ and lack of emotional awareness $(\beta=.27, p<.01)$, and negatively associated with quality of life $(\beta=-.22$, $\mathrm{p}<.05)$. Lack of emotional awareness partially mediated the relationship between attachment avoidance and quality of life (indirect effect $\beta=-.12, p=.008$ ). Attachment anxiety was not associated with any variable. Attachment avoidance may hinder the process of adaptation to breast cancer and difficulties in identifying and describing emotions may be partly responsible for this influence. Access to and ability to benefit from social and medical supports is likely to depend on being able to engage with others and recognize and process emotions effectively. Research and clinical implications are discussed.
\end{abstract}

Keywords: emotion regulation, quality of life, social support, oncology 


\section{Introduction}

Adapting to cancer challenges individuals in a number of different ways. Cancer and its treatments present difficult physical demands and they also challenge individuals' psychological coping capacities in several ways. High on the list of these challenges are being able to depend on others for support and being able to cope effectively with the complicated emotions engendered by cancer diagnosis and treatment (e.g., anger, sadness, fear) (Adler \& Page, 2008). Individuals differ in their comfort with seeking support when in need and in their effectiveness in dealing their emotions. These differences may be shaped in part by attachment security (Waldinger \& Schulz, 2016), which refers broadly to individuals' views about how worthy they are of love and care as well as their views about the likely availability and responsiveness of others (Bowlby, 1973).

In the specific context of breast cancer, attachment insecurity has been related to poorer psychological outcomes, particularly mood related disruptions such as anxiety, depressive symptoms, and greater psychological distress (see Nicholls, Hulbert-Williams, \& Bramwell, 2014 and Nissen, 2016, for a review). The specific reasons why attachment might facilitate or hinder adaptation to cancer, however, are less explored. One possible mechanism in need of further study is emotion processing strategies. It is now clear that successful adaptation to breast cancer depends, in part, on patients' abilities to cope with the strong and complex emotions that are likely to arise (see Brandão, Tavares, Schulz, \& Matos, 2016, for a review). Attachment is one factor that may shape this coping response (Ávila, Brandão, Teixeira, Coimbra, \& Matos, 2015; Cabral, Matos, Beyers, \& Soonens, 2012; Waldinger \& Schulz, 2016). While evidence has begun to accumulate about the role of emotion processes in mediating links between attachment and adaptation in other contexts (e.g., Cabral et al. 2012; Cloitre, Stovall-McClough, Zorbas, \& 
Charuvastra, 2008; Karreman \& Vingerhoets, 2012), studies examining this pathway in the context of cancer and breast cancer are lacking (one exception being Ávila et al., 2015).

Avoidant emotion processes have been linked to adaptational difficulties in breast cancer patients (Brandão et al., 2016). This study seeks to understand the role that two specific avoidant emotion processes play in adapting to breast cancer, namely emotion suppression and lack of emotional awareness. Emotion suppression or emotional control is defined as the conscious efforts of individuals to hide, inhibit, or reduce their emotional expressive behavior (Gross \& Levenson, 1993). Lack of emotional awareness refers to difficulties in the ability to recognize and describe emotions in one self (and others) (Lane \& Schwartz, 1987). Both emotion processes are explored as potential mediators of the association between insecure attachment and quality of life in women with breast cancer.

\section{Attachment and emotion processing}

According to attachment theory, internal working models, defined as cognitive representations of the self (one's worthy of love and care) and others (others' availability and responsiveness) derive from experiences with caregivers early in life and across the life span (Bowlby, 1973). It is assumed that these internal models guide thoughts, feelings, and behaviors in interpersonal relationships (Bowlby, 1973; Mikulincer \& Shaver, 2016; Pietromonaco, Barrett, \& Powers, 2006). Individual differences in adult attachment have been examined along two independent dimensions, attachment avoidance and attachment anxiety (Fraley, Hudson, Heffernan, \& Segal, 2015). These dimensions are believed to derive from different relationship dynamics and perceptions about attachment figure availability and responsiveness. They have unique influences on the ways individuals behave in a close relationship (Mikulincer \& Shaver, 2016), including patient-health care provider relationship (e.g., Maunder \& Hunter, 2016). 
Avoidantly attached individuals perceive attachment figures as unavailable, show discomfort with closeness and intimate relationships, and try to cope with aversive emotional reactions and attachment anxiety by dampening emotional reactions (Mikulincer \& Shaver, 2016; Pietromonaco \& Beck, 2015). Because avoidant attached individuals do not view seeking closeness as an effective strategy to relieve distress, they tend to use deactivating strategies to process their emotions and anxiety about closeness. These deactivating strategies include diverting attention away, dampening or minimizing emotional experience, and inhibiting verbal and non-verbal emotional expression (Mikulincer \& Shaver, 2016; Caldwell \& Shaver, 2012; Karreman \& Vingerhoets, 2012; Winterheld, 2016). Avoidantly attached individuals also tend to limit the attention paid to potentially threatening emotions or attachment-related phenomena. Bowlby (1973) referred to the attempts by avoidant individuals to keep emotion-related information out of awareness as defensive exclusion. Empirical studies have found links between attachment avoidance and a diminished awareness of emotional experiences (e.g., De Rick \& Vanheule, 2006; Fraley \& Brumbaugh, 2007; Mallinckrodt \& Wei, 2005; Monti \& Rudolph, 2014; Szpak \& Białecka-Pikul, 2015). Moreover, in general, more avoidantly attached patients are less likely to open up their emotions and needs to care providers and elicit support, resulting in an underuse of care services and less contact with care providers and, consequently, poor health outcomes (Brenk-Franz et al., 2015; Hunter \& Maunder, 2015; Salmon, Holcombe, Clark, Krespi, Fisher, \& Hill, 2007).

Anxiously attached individuals perceive attachment figures as inconsistently available (unreliable) or insufficiently responsive and, thus, worry about being rejected, abandoned or unloved (Mikulincer \& Shaver, 2016; Pietromonaco \& Beck, 2015). These individuals address these concerns by seeking excessive closeness and using hyperactivating strategies to deal with their anxiety about attachment. These strategies include strong demands for attention and care, 
clinging or controlling behaviors, intensification of attachment-related emotions and their expression (Mikulincer \& Shaver, 2016). These strategies are intended to make attachment figures pay more attention and provide more protection to them. Hyperactivating strategies include heightening the threatening aspects of an event and the accompanying negative emotions, and being hypervigilant with regards to physiological aspects of emotional states (Mikulincer \& Shaver, 2016). For these reasons, it would be expected that attachment anxiety would be associated with lower levels of emotional suppression. Very few studies, however, have explored the link between attachment anxiety and suppression. In one study that did explore a similar association, no link was found between fearful, preoccupied attachment (a construct that overlaps with attachment anxiety) and emotion suppression (Karreman \& Vingerhoets, 2012).

Moreover, anxiously attached individuals are more likely to be perceived by care providers as difficult patients given their tendency to embellish their emotions, their efforts to get support from care providers, and their overuse of health services (Ciechanowski, Walker, Katon, \& Russo, 2002; Hunter \& Maunder, 2015; Maunder, Panzer, Viljoen, Owen, Human, \& Hunter, 2006). Over time, it is possible that care providers may either pull back from these patients or communicate discomfort about meeting their needs.

In sum, there is evidence about the role played by attachment in guiding the choice of emotion regulation strategies. For this reason, we believe that the link between attachment and adaptation to breast cancer may be mediated by emotion regulatory efforts.

\section{Emotion regulation and adaptation to breast cancer}

The diagnosis and treatment of breast cancer brings with it a range of intense emotions (Adler \& Page, 2008). When faced with these emotions, women can respond to them in many different ways. The way women respond will depend on how they appraise the situation and their specific goals in each situation, because emotion regulation is goal-directed and context 
dependent (Aldao, 2013; Gross, 2015; Schulz \& Lazarus, 2012). Emotion regulation can take many forms. One way of organizing the forms is to consider whether they function to engage the individual and important others in the individual's life more fully in the emotional experience or whether they serve to distance the individual (and those in close relationships with the individual) from the emotion (Gross, 1998; Waldinger \& Schulz, 2010). In this study, two processes that distance individuals from their emotions - emotion suppression or control and lack of emotional awareness - are a central focus.

In the context of breast cancer, both emotion suppression and lack of emotional awareness have generally been associated with poorer psychosocial outcomes, such as poorer quality of life, more pain, and higher levels of psychological distress (e.g., Ávila et al., 2015; Baudic et al., 2016; Iwamitsu, Shimoda, Abe, \& Okawa, 2005; Li et al., 2015; Mantani et al., 2007; Marrazzo et al., 2016; Schlatter \& Cameron, 2010; Sousa, Guerra, \& Lencastre, 2015). One explanation for the negative effects of emotion suppression or control is suppression takes place late in the emotion generative and regulatory process. Suppression efforts are understood to be engaged after an affective experience has been initiated, and for this reason it is more challenging to dampen experiential and physiological arousal (John \& Gross, 2004; Srivastava, Tamir, McGonigal, John, \& Gross, 2009). Also, since emotion suppression or control targets expressive behavior, a component of the emotion that serves a social-communicative function, suppression can impair social functioning (Butler et al., 2003; Gross \& John, 2003; Srivastava, Tavir, McGonigal, John, \& Gross, 2009), limiting access to social support resources.

Regarding emotional awareness, it is recognized that individuals with higher levels of awareness of their affective experiences tend to deal better with challenging emotional experiences (Lane \& Schwartz, 1987). In fact, awareness and understanding of emotions are considered as key elements of effective emotion regulation (Gratz \& Roemer, 2004). Lack of 
emotional awareness, like suppression, may have social costs. A lack of awareness of emotions or resistance to acknowledging one's own emotions are likely to limit the ability of individuals to express their needs to significant others. This can limit the ability of others to recognize and respond to those needs, and eventually can lead to reduced support from others (Waldinger \& Schulz, 2016), all of which may contribute to greater difficulties in the process of adapting to breast cancer.

It is important to recognize that emotionally avoidant strategies can be useful in some specific contexts or situations (Dunn, Billotti, Murphy, \& Dalgleish, 2009). For instance, it is not uncommon for patients with cancer to suppress or control the expression of emotions, especially negative ones, in some situations as a strategy to sustain interpersonal relationships (Cordella \& Poiani, 2014). In sum, this study aims to understand the consequences of using emotional avoidance for adapting to breast cancer, and identify how these specific strategies are linked to attachment.

\section{The present study}

This study explores how specific emotion processes (emotional suppression or control and lack of emotional awareness) are linked to the process of adaptation to breast cancer, and help explain why attachment dimensions are predictive of adaptation. Thus, we examined the link between attachment insecurity levels (avoidance and anxiety) and quality of life and the potential mediating role of emotional dampening strategies (namely emotional suppression or control and lack of emotional awareness). More specifically, we hypothesized that higher levels of avoidant attachment would be associated with poorer quality of life, and that this link would be mediated by higher emotional suppression or control strategies and lower emotional awareness. We also hypothesized that women with higher levels of anxious attachment would report poorer quality of life, and that this link would be mediated by greater emotional awareness (related to hypervigilant 
strategies). Since most studies have not explored associations between levels of attachment anxiety and emotional suppression or control or did not find a link between them, we did not offer a hypothesis regarding the association between them but we explore this connection in the study.

\section{Methods}

\section{Participants}

Participants in this cross-sectional study were recruited online between December 2015 and March 2016. Recruitment was done through a web-based survey. An invitation was posted on different private and public Facebook group pages and other pages related to cancer, and on an online Portuguese platform called "Talk about Cancer." The invitation provided information about the objective of the study, the eligible population, and a link to the study website. On the website page, interested individuals were provided with an information sheet outlining the objectives of the study, information about approval by an institutional review committee, and an informed consent question.

Criteria for inclusion in the study were: being female, having a diagnosis of breast cancer and being more than 18 years old. The final sample included 155 women with breast cancer ranging in age from 27 to 68 years $(M=48.86$ years, $S D=7.49)$. The majority of women were involved in a romantic relationship (53\%), had children (79\%), and had completed active treatment (excluding hormone therapy) (79\%). The majority underwent breast surgery (94\%), chemotherapy (73\%), radiation therapy (68\%), and hormone therapy (68\%). Participants' sociodemographic data and cancer-related information are summarized in Table 1.

[INSERT TABLE 1 AROUND HERE]

\section{Measures}

\section{Attachment}


Attachment was measured with the Experiences in Close Relationships - Relationship Structure (ECR-RS; Fraley, Heffernan, Vicary, \& Brumbaugh, 2011; Portuguese version: Moreira, Martins, Gouveia, \& Canavarro, 2015). It is a 9-item self-report questionnaire designed to assess attachment anxiety (3 items; e.g., "I often worry that this person does not really care for me") and attachment avoidance (6 items; e.g., "It helps to turn to people in times of need" - item reversed) in close relationships (e.g., romantic partner, mother, and friend). First, participants were asked to identify an adult person with whom they have a close and strong emotional relationship; then they were asked to rate each item in regard to their thinking about that person. Items are rated on a Likert-type scale ranging from 1 (strongly disagree) to 7 (strongly agree). In this study, Cronbach's $\alpha$ was .90 for attachment anxiety and .80 for attachment avoidance.

\section{Emotion processes}

Emotion processes were tapped using two latent variables, one assessing emotion suppression and one assessing lack of emotional awareness. The expressive suppression subscale of the Emotion Regulation Questionnaire (ERQ; Gross \& John, 2003; Portuguese version: Brandão, Schulz, Gross, \& Matos, 2017) assessed the tendency of individuals to inhibit or control behavioral expression of an emotional response (4 items; e.g., "I keep my emotions to myself"). Items are rated on a 7-point Likert-type scale, ranging from strongly disagree (1) to strongly agree (7). Cronbach's alpha was .77 for the current sample.

Emotional control was assessed through the Courtauld Emotional Control Scale (Watson \& Greer, 1983; Portuguese version: Patrão, 2007). This is a 21-item scale assessing the tendency of individuals to control or suppress the expression of negative emotions (namely feelings of anger, anxiety, and depressed mood) when communicating with others. It is composed of three subscales: anger suppression (7 items; e.g., "When I feel angry I hide my annoyance"), anxiety suppression (7 items; e.g., "When I feel afraid or worried I refuse to say anything about it"), and 
mood suppression (7 items; e.g., "When I feel unhappy I smother my feelings"). Items are rated on a 4-point Likert-type scale, ranging from almost never (1) to almost always (4). All subscales presented good internal reliability in this study (Cronbach's alpha ranged between .83 and .87 ).

Lack of emotional awareness was evaluated using two subscales of the Toronto Alexithymia Scale- 20 (TAS-20; Bagby, Parker, \& Taylor, 1994; Portuguese version: Prazeres, Taylor, \& Parker, 2008): difficulty in identifying feelings (7 items; e.g. "I am often confused about what emotion I am feeling") and difficulty in describing feelings (5 items; e.g., "I am able to describe my feelings easily"). Items are rated on a 5-point Likert-type scale, ranging from completely disagree (1) to completely agree (5). Both subscales presented good internal reliability in this study (Cronbach's alpha $=.85$ and .67 for difficulty in identifying feelings and difficulty in describing feelings respectively).

\section{Quality of life}

Quality of life was measured using the World Health Organization Quality of Life - BREF (WHOQOL-BREF; Portuguese version: Vaz Serra et al., 2006). This is a 26-item self-report questionnaire that measures multiple domains of quality of life. In this study, we assessed three domains, physical health (7 items; e.g., "How much do you need any medical treatment to function in your daily life?"), the psychological domain (6 items; e.g., "How often do you have negative feelings such as blue mood, despair, anxiety, depression?"), and the social domain (3 items; e.g., "How satisfied are you with the support you get from your friends). Cronbach's alphas were .84 for the physical domain, .83 for the psychological domains, and .73 for the social domain.

\section{Sociodemographic and cancer-related information}

Sociodemographic (age, education, employment status, marital status, length of 
relationship) and cancer-related information (surgery, type of treatments, history of recurrence, and co-morbidity) were collected through participants' self-report.

\section{Procedure}

The study was approved by the Ethical Committee of the Faculty of Psychology and Educational Sciences, University of Porto. Data were collected online using LimeSurvey (LimeSurvey Project Team Carsten Schmitz, 2015) hosted by the University of Porto. The goals of the study and participation requirements were described in the landing page. Informed consent by participants was required to proceed to the survey. The time required to complete the questionnaires varied from 15 to 25 minutes. Participants were volunteers and received no incentives or monetary compensation for their participation in the study.

\section{Statistical analysis}

Data analysis was conducted using SPSS and AMOS (version 23; IBM, SPSS Inc.,

Chicago, IL). Since participants had to provide an answer before they were allowed to proceed to the next question there were no missing data. The proposed mediational model was tested with structural equation modelling (SEM) using the maximum likelihood robust estimation method. This approach is particularly useful for testing mediational models when the variables are latent constructs (Gunzler, Chen, Wu, \& Zhang, 2013). The following commonly employed goodnessof-fit indicators were used to assess the overall fit of the model (Hooper, Coughlan, \& Mullen, 2008): the chi-square/df statistic $(<2.0)$, the Bentler comparative fit index $(\mathrm{CFI})$, the goodness of fit index (GFI) (> .90), the standardized root mean square residual (SRMR; <.06), and the root mean square error of approximation (RMSEA; <.07). Mediation was tested and quantified by estimating direct and indirect effects using bootstrap resampling procedures (MacKinnon, Lockwood, \& Williams, 2004). Bias-corrected 95\% confidence intervals (CI’s) for the unstandardized effects were obtained based on 5000 bootstrap samples (MacKinnon et al., 2004). 
Two manifest variables (representing attachment dimensions) and three latent variables (quality of life and the two hypothesized emotion mediators) were included in the model. Overall quality of life was tapped by the physical, psychological, and social subscales of the WHOQOLBREF. The two hypothesized emotion mediators were: (1) emotion suppression, a latent variable composed of the expressive suppression subscale from the ERQ and by the anger, anxiety, and depressed mood control subscales from the CECS; and (2) lack of emotional awareness, a latent variable composed of the difficulty in identifying emotions and difficulty in describing emotions subscales from the TAS-20.

\section{Results}

In preliminary analyses, distributions for all variables of this study were examined. There were no meaningful departures from normality (i.e., skewness and kurtosis (absolute) values all below 1.1). Levels of attachment anxiety $(M=2.90 ; S D=2.04)$ and avoidance $(M=2.29 ; S D=$ 1.15) for our sample were similar to those found in other studies with breast cancer patients (e.g., Ávila et al., 2015: $M$ anxiety $=2.84 ; S D=1.56 ; M$ avoidance $=2.35 ; S D=1.49$ ) or community samples (e.g., Moreira et al., 2014: $M$ anxiety $=2.12 ; S D=1.08 ; M$ avoidance $=2.32 ; S D=0.75$ ).

Small to moderate positive correlations were found between attachment avoidance and all emotion variables. Small to moderate negative correlations were found between attachment avoidance and dimensions of quality of life (Pearson's $r$ ranging between -.23 and -.43). Attachment anxiety was only weakly positively correlated with difficulty in identifying and describing feelings and negatively with the social dimension of quality of life. Small to medium negative effects were found between some emotion variables and indicators of quality of life (Pearson's $r$ ranging between -.16 and -.35). Descriptive statistics and correlations among study variables are presented in Table 2.

[INSERT TABLE 2 ABOUT HERE] 
Results obtained for the mediational model are presented in Figure 1. All indicator variables loaded strongly on the relevant latent construct. The model provided a good fit to the data $\left(\chi^{2}(36)=56.11 ; p=.017 ; \chi^{2} / \mathrm{df}=1.56 ; \mathrm{CFI}=.97 ; \mathrm{GFI}=.94 ;\right.$ SRMR $=.05 ; \mathrm{RMSEA}=.06$, $90 \%$ CI $[.026, .090], p$ close $=.273)$ and accounted for $38 \%$ of the total variance in women's quality of life. Since previous research (Brandão, Schulz, \& Matos, 2017) suggested that age, relationship status and education might be associated with adaptation to breast cancer, the model was also tested with these three variables entered as covariates. These covariates were not significantly related to quality of life and did not substantively alter the overall model, so the more parsimonious model is presented as the final model.

\section{[INSERT FIGURE 1 ABOUT HERE]}

As expected, attachment avoidance was positively associated with both emotion suppression $(\beta=.29, p<.01)$ and lack of emotional awareness $(\beta=.27, p<.01)$, and negatively associated with quality of life $(\beta=-.22, p<.05)$. Attachment anxiety was not associated with emotion suppression $(\beta=.05, n s)$, and contrary to prediction was not associated with lack of emotional awareness $(\beta=.15, n s)$ or quality of life $(\beta=.00, n s)$. Lack of emotional awareness, as expected was negatively associated with quality of life $(\beta=-.54, p<.001)$.

Results from bootstrapping analyses provided additional support for lack of emotional awareness as a partial mediator of the relationships between attachment avoidance and quality of life. The indirect pathway from attachment avoidance to quality of life through emotional awareness was significant $(\beta=-.123, \mathrm{SE}=.05,95 \% \mathrm{CI}[-.247,-.032], p=.008)$.

\section{Discussion}

This study aimed to examine the association between levels of attachment insecurity and quality of life in women with breast cancer. It also aimed to explore the mediating role of 
avoidant emotion processes in this association. The link between attachment insecurity and difficulties in adaptation to breast cancer is now well recognized (Nicholls et al., 2014; Nissen, 2016). Little is known, however, about the underlying pathway involved in the association between attachment and quality of life after breast cancer diagnosis. There is evidence linking adaptational difficulties in response to breast cancer with styles of emotion processing, particularly those indicative of attempts to avoid experiencing or expressing negative emotions (Brandão et al., 2016). These styles of emotion processing may be related to attachment styles. Results from this study indicate that, as hypothesized, higher levels of attachment avoidance were significantly associated with poorer quality of life. Women dealing breast cancer who reported that they were more uncomfortable relying on significant others reported poorer quality of life after breast cancer diagnosis than those who were more comfortable embracing close others for support. This finding is in accordance with previous research that suggests that attachment avoidance may have corrosive effects on health in general (e.g., Maunder \& Hunter, 2008; McWilliams \& Bailey, 2010) and specifically for the process of adaptation to cancer (e.g., Nicholls et al., 2014; Nissen, 2016). In the present study, higher levels of attachment avoidance were also associated with both emotion suppression and lack of emotional awareness, as hypothesized. This finding is consistent with previous research (De Rick \& Vanheule, 2006; Mallinckrodt \& Wei, 2005; Mikulincer \& Shaver, 2016; Monti \& Rudolph, 2014; Szpak \& Białecka-Pikul, 2015) and supports the idea that more avoidantly attached individuals may suppress the expression of their emotions. This may happen because they view proximity seeking as a non-effective strategy to relieve distress and try to deactivate their attachment system (Mikulincer \& Shaver, 2016; Pietromonaco \& Barrett, 2000). More avoidantly attached individuals may, however, inhibit emotion expression not only because they want to avoid heightening emotions in close relationships but also because they may not have clear access to 
these emotions. The findings indicate that individuals reporting higher levels of avoidant attachment also reported more difficulties in recognizing, identifying and describing their own emotional experiences than individuals who embrace close relationships. Difficulty accessing emotions may be the result of defensive processes designed to keep the attachment system deactivated and reduce feelings of vulnerability (Fraley \& Shaver, 1998). Another possible reason for the lack of awareness in avoidant individuals could be related to a lack of opportunity to develop this awareness in past relationships. A lack of availability of an attachment figure or poor responsivity from that attachment figure reduce opportunities to label, express and talk about emotions. This can lead to a lack of emotional awareness in these more avoidantly attached women. This lack of emotional awareness may hinder adaptation to cancer by reducing access to social support and help from health professionals that might be contingent on acknowledging and elaborating one's emotional experience. These emotion difficulties are likely to extend to difficulties identifying emotional needs and asking for support, which can lead to social costs (Butler et al., 2003; Waldinger \& Schulz, 2016).

Support was found for the mediating role of lack of emotional awareness, but not emotion suppression, in partially mediating the relationship between levels of attachment avoidance and quality of life after breast cancer diagnosis. More studies are needed to understand this differential pattern. These results suggest that more avoidantly attached individuals may present poorer quality of life after breast cancer diagnosis because they tend to have poorer awareness of emotions (and not because they suppress them), which may then lead to lower levels of quality of life. In fact, in this study, higher levels of attachment avoidance seem related to the process of adaptation to breast cancer through lack of emotional awareness, but not through emotion suppression (that neither facilitated nor hindered adaptation). It seems that for more avoidantly 
attached women being able to recognize and describe their emotions may be more important for their successful adaption to breast cancer, than is their ability to express their emotions.

It is important to note that lack of emotional awareness only partially mediated the association between levels of attachment avoidance and quality of life after breast cancer diagnosis. Also, there was a still a significant and sizeable link between levels of attachment avoidance and quality of life. For this reason, future studies should explore additional mediating variables (e.g., relationship satisfaction, caregiving dynamics) to better understand how attachment can facilitate or hinder adaptation to breast cancer. Social support dynamics seem particularly important to address taking into account the role attachment plays in shaping interpersonal relationships across the life span. In fact, more secure individuals tend to be more comfortable with closeness and willing to depend on others for support (Waldinger \& Schulz, 2016).

Surprisingly, levels of attachment anxiety were not associated with quality of life. Attachment anxiety has been linked to poorer overall physical and mental health (e.g., negative overall health perceptions, difficulties in role functioning, or higher levels of psychological distress) (e.g., Stanton \& Campbell, 2014). In the context of cancer, similar findings have emerged with links between attachment anxiety and higher levels of depression, anxiety, and lower levels of perceived social support (Nicholls et al., 2014; Nissen, 2016). In our study, this negative effect of levels of attachment anxiety was not found. It is possible that the use of hyperactivating strategies, in the context of a life-threatening disease such as the breast cancer, may favor a continued provision of support from significant others. This could contribute to reduce the possible negative effects of attachment anxiety on quality of life. Also, it is possible that attachment anxiety may impair quality of life through hyperactivation strategies of emotion 
regulation strategies (e.g., rumination as found in Ávila et al., 2015) and not through emotion avoidant processes.

Levels of attachment anxiety were not associated with emotion suppression or lack of emotional awareness. According to Simpson and Rholes (2017), highly anxiously attached individuals tend to use hyperactivating strategies especially when they face specific types of stressful situations that threaten the stability or quality of their relationship with their attachment figure. Such hyperactivating strategies would likely increase attention to emotional experience (and presumably emotional awareness) and might reduce suppression. These connections, however, were not found in this study. One possibility is that anxiety about attachment may have complex and contradictory effects on emotion awareness and suppression. There may be more motivation to attend to or express emotions but this motivation may be limited to certain types of emotion or may be infused with worries about the likely success of these strategies. The worries might be particularly important in shaping self-reports of emotion awareness and suppression; that is, more avoidantly attached individuals may have doubts about their capacities for emotional awareness or expression that might contrast their observed abilities or behavior. These doubts could in fact fuel attention to emotion and expression (e.g., through rumination as found in Ávila et al., 2015) but not necessarily result in a subjective sense of greater awareness or unconstrained expression. Future research is needed to clarify how anxiety about attachment might shape these emotion processes.

\section{Limitations and future research}

Some limitations of this study should be acknowledged. First, the study design was crosssectional, thus temporal and causal relationships among attachment, emotion regulation, and quality of life could not be determined. Future studies with longitudinal designs are needed to determine the temporal nature of the relationships between these variables. Second, the majority 
of women participating in this study had finished their primary treatment for breast cancer, which may limit the generalizability of the results for women in other stages of the disease. The data we reported in the results section regarding the similarity in the levels of attachment anxiety and avoidance in this sample as compared to other studies give us some confidence that this sample is not unusual in regards to attachment. However, it is important to acknowledge that the sample may be experiencing other online social support dynamics and it is possible that our online recruitment strategy may have biased the sample in other unmeasured ways. As always, replication of these findings in other samples (and including other recruitment strategies) is critical.

It is also important to note that breast cancer is not just a disease that women experience. Although the prevalence of breast cancer in men is considerable lower, in future studies, it will be useful to examine associations among attachment, emotion regulation, and adaptation in samples of men.

Considering the relational context of most emotions and of attachment dynamics, future studies would benefit by exploring these links using more dyadic approaches that allow researchers to examine and distinguish between intra-individual influences and cross-partner influences (e.g., collecting data from patients and their partners, and using data analytic strategies such as the Actor-Partner Independence Model). Finally, in this study, data were collected only through self-report measures which are susceptible to response and social desirability biases. The inclusion of observational or partner-report measures (from romantic partners, family members, friends) in future studies is also critical.

\section{Clinical implications}


Levels of attachment insecurity (avoidance in this study) are linked to poorer adaptation to breast cancer. Because internal working models are relatively stable and resistant to change in therapy (Mallinckrodt, Gantt, \& Coble, 1995), it is critical to identify the pathways by which attachment constructs influence adaptation. These pathways are likely to point to more malleable targets that can be the focus of intervention efforts designed to promote adaptation to breast cancer. This study identifies emotion processing, particularly emotional awareness, as a potential focus for therapists who work with breast cancer. In primary care settings, the assessment of emotion processing can help to identify women that are at greater risk for difficulties in the process of adaptation to cancer and lead to referrals for them to obtain psychosocial support.

The results suggest that emotion-focused interventions aimed at developing skills for improving emotional awareness might be useful for women with breast cancer. In this type of intervention, therapists could target different aspects of emotional experiences, assisting patients to be more aware and to understand better their emotional experiences (e.g., supportiveexpressive interventions). This assistance may also help give meaning to these emotional experiences, a process that has been linked to better psychological adaptation (e.g., Reuter, Scholl, Sillem, Hasenburg, \& Harter, 2010). Given the links with levels of attachment avoidance, therapists might also consider working on understanding motivations that are contributing to emotional avoidance. Promoting emotional awareness can contribute to the acceptance of emotions and to the opportunity to employ emotion regulatory processes that may be more adaptive than rigid avoidance.

Health care professionals should be aware of the importance of emotion regulation strategies for the process of adaptation to breast cancer. As an important source of support, health care professionals should pay attention not only to the intensity but also to the nature of emotional responses of breast cancer patients and their resources to deal with those emotional 
responses. When faced with patients with an emotionally inhibiting style, they should seek to understand underlying motivations and goals for those inhibitory efforts and, if necessary, they should refer patients for psychological support.

\section{References}

Adler, N. E., \& Page, A. E. (2008). Cancer care for the whole patient: Meeting psychosocial health needs. Washington DC: The National Academies Press.

Aldao, A. (2013). The future of emotion regulation research: Capturing context. Perspectives on Psychological Science, 8, 155-72. Doi: 10.1177/1745691612459518

Ávila, M., Brandão, T., Teixeira, J., Coimbra, J., \& Matos, P. M. (2015). Attachment, emotion regulation and adaptation to breast cancer: Assessment of a meditational hypothesis. Psycho-Oncology, 24, 1514-1520. Doi: 10.1002/pon.3817

Bagby, R. M., Parker, J. D. A., \& Taylor, G. J. (1994). The twenty-item Toronto Alexithymia Scale-I. Item selection and cross-validation of the factor structure. Journal of Psychosomatic Research, 38, 23-32. Doi: 10.1016/0022-3999(94)90005-1

Baudic, S., Jayr, C., Albi-Feldzer, A., Fermanian, J., Masselin-Dubois, A., Bouhassira, D., \& Attal, N. (2016). Effect of alexithymia and emotional repression on postsurgical pain in women with breast cancer: A prospective longitudinal 12-month study. The Journal of Pain, 17, 90-100.

Bowlby, J. (1973). Attachment and loss, Vol 2: Separation: Anxiety and anger. New York: Penguin Books.

Brandão, T., Tavares, R., Schulz, M. S., \& Matos, P. M. (2016). Measuring emotion regulation and emotional expression in breast cancer patients: A systematic review. Clinical Psychology Review, 43, 114-127. Doi: http://dx.doi.org/10.1016/j.cpr.2015.10.002 
Brandão, T., Schulz, M. S., \& Matos, P. M. (2017). Psychological adjustment after breast cancer: A systematic review of longitudinal studies. Advanced online publication. PsychoOncology. Doi: 10.1002/pon.4230

Brandão, T., Schulz, M. S., Gross, J. J., \& Matos, P. M. (2017). The Emotion Regulation Questionnaire in women with cancer: A psychometric evaluation and an item response theory analysis. Advanced online publication. Psycho-Oncology. Doi: 10.1002/pon.4356

Brenk-Franz, K., Strauss, B., Tiesler, F., Fleischhauer, C., Ciechanowski, P., Schneider, N., \& Gensichen, J. (2015). The influence of adult attachment on patient self-management in primary care-the need for a personalized approach and patient-centred care. PloS One, 10, e0136723. Doi: 10.1371/journal.pone.0136723

Butler, E. A., Egloff, B., Wlhelm, F. H., Smith, N. C., Erickson, E. A., \& Gross, J. J. (2003). The social consequences of expressive suppression. Emotion, 3, 48. Doi: 10.1037/15283542.3.1.48

Cabral, J., Matos, P.M., Beyers, W., \& Soonens, B. (2012). Attachment, emotion regulation and coping in Portuguese emerging adults: A test of a mediation hypothesis. Spanish Journal of Psychology, 15, 1000-1012. Doi: 10.5209/rev_SJOP.2012.v15.n3.39391

Caldwell, J. G., \& Shaver, P. R. (2012). Exploring the cognitive-emotional pathways between adult attachment and ego-resiliency. Individual Differences Research, 10, 141-152.

Cassidy, J. (1994). Emotion regulation: Influences of attachment relationships. Monographs of the Society for Research in Child Development, 59, 228-249.

Ciechanowski, P. S., Walker, E. A., Katon, W. J., \& Russo, J. E. (2002) Attachment theory: A model for health care utilization and somatization. Psychosomatic Medicine, 64, 660-667. 
Classen, C., Diamond, S., Soleman, A., Fobair, P., Spira, J., \& Spiegel, D. (1993). Brief supportive-expressive group therapy for women with primary breast cancer: A treatment manual. Stanford: University School of Medicine.

Cloitre, M., Stovall-McClough, C., Zorbas, P., \& Charuvastra, A. (2008). Attachment organization, emotion regulation, and expectations of support in a clinical sample of women with childhood abuse histories. Journal of Traumatic Stress, 21, 282-289.

Cordella, M., \& Poiani, A. (2014). Behavioural oncology: Psychological, communicative, and social dimensions. New York: Springer. Doi: 10.1007/978-1-4614-9605-2

De Rick, A., \& Vanheule, S. (2006). The relationship between perceived parenting, adult attachment style and alexithymia in alcoholic inpatients. Addictive behaviors, 31, 1265 1270.

Diaz, A., \& Eisenberg, N. (2015). The process of emotion regulation is different from individual differences in emotion regulation: Conceptual arguments and a focus on individual differences. Psychological Inquiry, 26, 37-47. Doi: 10.1080/1047840X.2015.959094

Dorval, M., Guay, S., Mondor, M., Mâsse, B., Falardeau, M., Robidouz, A., Deschênes, L., \& Maunsell, E. (2005). Couples who get closer after breast cancer: Frequency and predictors in a prospective investigation. Journal of Clinical Oncology, 20, 3588-3596. Doi: 10.1200/JCO.2005.01.628

Dunn, B. D., Billotti, D., Murphy, V., \& Dalgleish, T. (2009). The consequences of effortful emotion regulation when processing distressing material: A comparison of suppression and acceptance. Behaviour Research and Therapy, 47, 761-773.

Fraley, R. C., \& Shaver, P. R. (1998). Airport separations: A naturalistic study of adult attachment dynamics in separating couples. Journal of Personality and Social Psychology, 75, 11981212. 
Fraley, R. C., \& Brumbaugh, C. C. (2007). Adult attachment and preemptive defenses: Converging evidence on the role of defensive exclusion at the level of encoding. Journal of Personality, 75, 1033-1050. Doi: 10.1111/j.1467-6494.2007.00465.x

Fraley, R. C., Heffernan, M. E., Vicary, A. M., \& Brumbaugh, C. C. (2011). The experiences in close relationships-relationship structures questionnaire: A method for assessing attachment orientations across relationships. Psychological Assessment, 23, 615-625. Doi: http://dx.doi.org/10.1037/a0022898

Fraley, R. C., Hudson, N. W., Heffernan, M. E., \& Segal, N. (2015). Are adult attachment styles categorical or dimensional? A taxometric analysis of general and relationship-specific attachment orientations. Journal of Personality and Social Psychology, 109, 354-368. Doi: doi: 10.1037/pspp0000027

Gratz, K.L. \& Roemer, E. (2004). Multidimensional assessment of emotion regulation and dysregulation: Development, factor structure, and initial validation of the difficulties in emotion regulation Scale. Journal of Psychopathology and Behavioral Assessment, 26, 41-54.

Gross, J. J. (2015) Emotion regulation: Current status and future prospects. Psychological Inquiry, 26, 1-26. Doi: 10.1080/1047840X.2014.940781

Gross, J. J., \& John, O. P. (2003). Individual differences in two emotion regulation processes: Implications for affect, relationships, and well-being. Journal of Personality and Social Psychology, 85, 348-362. Doi: http://dx.doi.org/10.1037/0022-3514.85.2.348

Gross, J. J. (1998). Antecedent-and response-focused emotion regulation: Divergent consequences for experience, expression, and physiology. Journal of Personality and Social Psychology, 74, 224-237. Doi: http://dx.doi.org/10.1037/0022-3514.74.1.224 
Gross, J.J., \& Levenson, R.W. (1993). Emotional suppression: Physiology, self-report, and expressive behavior. Journal of Personality and Social Psychology, 64, 970-986.

Gunzler, D., Chen, T., Wu, P., \& Zhang, H. (2013). Introduction to mediation analysis with structural equation modeling. Shanghai Archives of Psychiatry, 25, 390.

Hooper, D., Coughlan, J., \& Mullen, M. R. (2008). Structural equation modeling: Guidelines for determining model fit. The Electronic Journal of Business Research Methods, 6, 53-60.

Hunter, J., \& Maunder, R. (2015). Advanced concepts in attachment theory and their application to health care. In J. Hunter, \& R. Maunder (Eds.). Improving patient treatment with attachment theory: a guide for primary care practitioners and specialists (pp 27-37). New York: Springer. Doi: 10.1007/978-3-319-23300-0_3

Iwamitsu, Y., Shimoda, K., Abe, H., Tani, T., Okawa, M., \& Buck, R. (2005). The relation between negative emotional suppression and emotional distress in breast cancer diagnosis and treatment. Health Communication, 18, 201-215. Doi: 10.1207/s15327027hc1803_1

John, O.P., \& Gross, J.J. (2004). Healthy and unhealthy emotion regulation: Personality processes, individual differences, and lifespan development. Journal of Personality, 72, 1301-1334.

Karreman, A., \& Vingerhoets, A. J. J. M. (2012). Attachment and well-being: The mediating role of emotion regulation and resilience. Personality and Individual Differences, 53, 821-826. doi:10.1016/j.paid.2012.06.014

Koole, S. L., Webb, T. L., \& Sheeran, P. L. (2015). Implicit emotion regulation: Feeling better without knowing why. Current Opinion in Psychology, 3, 6-10. Doi: http://dx.doi.org/10.1016/j.copsyc.2014.12.027 
Lane, R. D., \& Schwartz, G. E. (1987). Levels of emotional awareness: A cognitivedevelopmental theory and its application to psychopathology. The American Journal of Psychiatry, 144, 133-143.

Li, L., Yang, Y., He, J., Yi, J., Wang, Y., Zhang, J., \& Zhu, X. (2015). Emotional suppression and depressive symptoms in women newly diagnosed with early breast cancer. BMC women's health, 15, 91 .

LimeSurvey Project Team Carsten Schmitz (2015). LimeSurvey: An Open Source survey tool. LimeSurvey Project Hamburg, Germany. http://www.limesurvey.org

MacKinnon, D. P., Lockwood, C. M., \& Williams, J. (2004). Confidence limits for the indirect effect: Distribution of the product and resampling methods. Multivariate Behavioral research, 39, 99-128.

Mallinckrodt, B., Gantt, D. L., \& Coble, H. M. (1995). Attachment patterns in the psychotherapy relationship: Development of the Client Attachment to Therapist Scale. Journal of Counseling Psychology, 42, 307.

Mallinckrodt, B., \& Wei, M. (2005). Attachment, social competencies, social support, and psychological distress. Journal of Counseling Psychology, 52, 358. Doi: 10.1037/00220167.52.3.358

Mantani, T., Saeki, T., Inoue, S., Okamura, H., Daino, M., Kataoka, T., \& Yamawaki, S. (2007). Factors related to anxiety and depression in women with breast cancer and their husbands: Role of alexithymia and family functioning. Supportive Care in Cancer, 15, 859-868.

Maunder, R. G., \& Hunter, J. J. (2016). Can patients be 'attached' to healthcare providers? An observational study to measure attachment phenomena in patient-provider relationships. BMJ Open, 6, e011068. Doi: 10.1136/bmjopen-2016-011068 
Maunder, R. G., \& Hunter, J. J. (2008). Attachment relationships as determinants of physical health. Journal of the American Academy of Psychoanalysis \& Dynamic Psychiatry, 36, 11-32. doi:10.1521/ jaap.2008.36.1.11

Maunder, R. G., Panzer, A., Viljoen, M., Owen, J., Human, S., \& Hunter, J. J. (2006). Physicians' difficulty with emergency department patients is related to patients' attachment style. Social Science \& Medicine, 63, 552-562. Doi: 10.1016/j.socscimed.2006.01.001

Marrazzo, G., Sideli, L., Rizzo, R., Marinaro, A. M., Mulè, A., Marrazzo, A., ... \& La Barbera, D. (1989). Quality of life, alexithymia, and defense mechanisms in patients affected by breast cancer across different stages of illness. Journal of Psychopathology, 22, 141-148.

McWilliams, L. A., \& Bailey, S. J. (2010). Associations between adult attachment ratings and health conditions: Evidence from the National Comorbidity Survey Replication. Health Psychology, 29, 446-453. Doi: 10.1037/a0020061

Mikulincer, M. \& Shaver, P. R. (2016). Attachment in adulthood: Structure, dynamics, and change ( $2^{\text {nd }}$ Ed). New York: Guilford Press.

Mikulincer, M., Shaver, P. R. \& Pereg, D. (2003). Attachment theory and affect regulation: The dynamics, development, and cognitive consequences of attachment-related strategies. Motivation and Emotion, 27, 77-102. doi: 10.1023/A:1024515519160

Monti, J. D., \& Rudolph, K. D. (2014). Emotional awareness as a pathway linking adult attachment to subsequent depression. Journal of Counseling Psychology, 61, 374-382. Doi: $10.1037 / \mathrm{cou} 0000016$

Moreira, H., Martins, T., Gouveia, M. J., \& Canavarro, M. C. (2015). Assessing adult attachment across different contexts: Validation of the Portuguese version of the Experiences in Close Relationships - Relationship Structures Questionnaire. Journal of Personality Assessment, 97, 22-30. Doi: http://dx.doi.org/10.1080/00223891.2014.950377 
Nicholls, W., Hulbert-Williams, N., \& Bramwell, R. (2014). The role of relationship attachment in psychological adjustment to cancer in patients and caregivers: A systematic review of the literature. Psycho-Oncology, 23, 1083-1095. Doi: 10.1002/pon.3664

Nissen, K. G. (2016). Correlates of self-rated attachment in patients with cancer and their caregivers: A systematic review and meta-analysis. Psycho-Oncology. Doi: 10.1002/pon.4057.

Patrão, I. (2007). O ciclo psico-oncológico no cancro da mama: Estudo do impacto psicossocial do diagnóstico e dos tratamentos [The psycho-oncology cycle of the breast cancer: Psychosocial impact of diagnosis and treatmens] (Unpublished doctoral dissertation). Universidade Nova de Lisboa, Lisboa.

Overall, N. C., \& Lemay, E. P. (2015). Attachment and dyadic regulation processes. In J. A. Simpson \& W. S. Rholes (Eds), Attachment, theory, and research: New directions and emerging themes (pp. 145-169. New York: The Guilford Press.

Pietromonaco, P. R., \& Barrett, L. F. (2000). Internal working models: What do we really know about the self in relation to others? Review of General Psychology, 4, 155-175.

Pietromonaco, P. R., Barrett, L. F., \& Powers, S. A. (2006). Adult attachment theory and affective reactivity and regulation. In J. Simpson, D. Snyder, \& J. Hughes (Eds.), Emotion regulation in families and close relationships: Pathways to dysfunction and health (pp. 57-74). Washington, DC: American Psychological Association.

Pietromonaco, P. R., \& Beck, L. A. (2015). Attachment processes in adult romantic relationships. In M. Mikulincer, \& P. R. Shaver (Eds). APA handbook of personality and social psychology, Volume 3: Interpersonal relations (pp.33-64). Washington, DC, US: American Psychological Association. Doi: 10.1037/14344-002 
Prazeres, N., Taylor, G. J., \& Parker, J. D. A. (2008). Escala de Alexitimia de Toronto de Vinte Itens (TAS-20) [Toronto Alexithymia Scale of 20 item]. In L. S. Almeida, M. R. Simões, C. Machado, \& M. M. Gonçalves (Eds.), Avaliação psicológica: Instrumentos validados para a população portuguesa [Psychological assessment: Validated instruments to the portuguese population] (Vol II, 2ª Ed., pp.95-107). Coimbra: Quarteto.

Fraley, R. C., \& Shaver, P. R. (1998). Airport separations: A naturalistic study of adult attachment dynamics in separating couples. Journal of Personality and Social Psychology, 75, 11981212

Reuter, K., Scholl, I., Sillem, M., Hasenburg, A., \& Härter, M. (2010). Implementation and benefits of psychooncological group interventions in German breast centers: A pilot study on supportive-expressive group therapy for women with primary breast cancer. Breast Care, 5, 91-96. Doi: 10.1159/000297739

Salmon, P., Holcombe, C., Clark, L., Krespi, R., Fisher, J., \& Hill, J. (2007). Relationships with clinical staff after a diagnosis of breast cancer are associated with patients' experience of care and abuse in childhood. Journal of Psychosomatic Research, 63, 255-262. Doi: 10.1016/j.jpsychores.2007.05.002

Schlatter, M. C., \& Cameron, L. D. (2010). Emotional suppression tendencies as predictors of symptoms, mood, and coping appraisals during AC chemotherapy for breast cancer treatment. Annals of Behavioral Medicine, 40, 15-29.

Schulz, M. S., \& Lazarus, R. S. (2012). Emotion regulation during adolescence: A cognitive mediational conceptualization. In P. K. Kerig M. S. Schulz, \& S. T. Hauser (Eds). Adolescence and beyond: Family processes and development (pp. 19-42). Oxford: University Press. 
Shaver, P. R., \& Mikulincer, M. (2014). Adult attachment and emotion regulation. In J. J. Gross (Ed.), Handbook of emotion regulation (pp. 237-250). New York: The Guilford Press.

Simpson, J. A., \& Rholes, W. S. (2017). Adult attachment, stress, and romantic relationships. Current Opinion in Psychology, 13, 19-24. Doi: 10.1016/j.copsyc.2016.04.006

Sousa, H., Guerra, M., \& Lencastre, L. (2015). Preditores da qualidade de vida numa amostra de mulheres com cancro da mama. Análise Psicológica, 33, 39-53.

Srivastava, S., Tamir, M., McGonigal, K. M., John, O. P., \& Gross, J. J. (2009). The social costs of emotional suppression: A prospective study of the transition to college. Journal of Personality and Social Psychology, 96, 883-897. doi: 10.1037/a0014755

Stanton, S. C. E., \& Campbell, L. (2014). Perceived social support moderates the link between attachment anxiety and health outcomes. PLoS ONE, 9, e95358. doi: 10.1371/journal.pone.0095358

Szpak, M., \& Białecka-Pikul, M. (2015). Attachment and alexithymia are related, but mindmindedness does not mediate this relationship. Polish Psychological Bulletin, 46, $217-$ 222.

Thorberg, F. A., Young, R. M., Sullivan, K. A., Lyvers, M., Hurst, C., Connor, J., \& Feeney, G. (2011). Attachment security and alexithymia in a heavy drinking sample. Addiction Research \& Theory, 19, 566-570.

Vaz Serra, A., Canavarro, M. C., Simões, M. R., Pereira, M., Gameiro, S., Quartilho, M. J., ... Paredes, T. (2006). Estudos psicométricos do instrumento de avaliação da qualidade de vida da Organização Mundial de Saúde (WHOQOL-Bref) para Português de Portugal [Psychometric properties of The World Health Organization quality of life assessment (WHOQOL-Bref) to Portuguese of Portugal]. Psiquiatria Clínica, 27, 41-49. 
Waldinger, R. J., \& Schulz, M. S. (2010). Facing the music or burying our heads in the sand?: Adaptive emotion regulation in midlife and late life. Research in Human Development, 7, 292-306. Doi: 10.1080/15427609.2010.526527

Waldinger, R. J., \& Schulz, M. S. (2016). The long reach of nurturing family environments: links with midlife emotion-regulatory styles and late-life security in intimate relationships. Psychological science, 27, 1443-1450. Doi: 10.1177/0956797616661556

Watson, M., \& Greer, S. (1983). Development of a questionnaire measure of emotional control. Journal of Psychosomatic Research, 27, 299-305. Doi: 10.1016/0022-3999(83)90052-1

Winterheld, H. A. (2016). Calibrating use of emotion regulation strategies to the relationship context: An attachment perspective. Journal of Personality, 84, 369-480. Doi: 10.1111/jopy.12165 